\title{
Resección quirúrgica de aspergiloma en paciente inmunosuprimido: presentación de un caso clínico
}

\author{
Dr. Jorge García', Dra. Ángela Cardona², Dra. Eliana Gómez³, Dra. Andrea Parra \\ 1 Neumologo Pediatra Intensivista, Hospital Pablo Tobón Uribe. \\ 2 Neumologa Pediatra, Hospital Pablo Tobón Uribe. \\ 3 Residentes de Pediatría de la Universidad Pontificia Bolivariana.
}

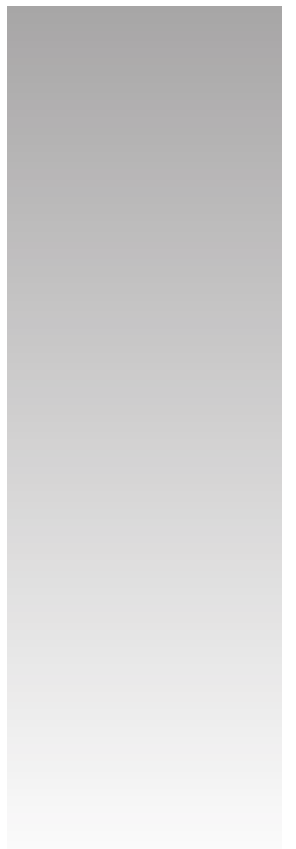

\section{SURGICAL RESECTION OF ASPERGILLOMA IN IMMUNOSUPPRESSED PATIENT: A CASE REPORT}

Aspergillosis refers to the spectrum of disease caused by Aspergillus species. The aspergilloma is the most common and best-recognized form of pulmonary involvement due to Aspergillus; usually developing in a preformed lung cavity and the principal association is with Tuberculosis. The true incidence of aspergilloma is not known. Although frequently asymp- tomatic, the presence of a fungus ball due to Aspergillus may cause hemoptysis and in cases can be fatal, with a variable mortality ranging between 9 to $30 \%$. Aspergilloma usually comes to clinical attention as an incidental finding, thus the diagnosis involve clinical and radiological findings confirmed by pathology. There is no consistent evidence that aspergilloma. Responds to antifungal agents, and these drugs rarely achieve the minimal inhibitory concentrations within the lung cavities. Surgical resection, despite a high morbidity, is the only proven therapy for these cases.

Key words: Pulmonary aspergilloma, hemoptysis, surgical treatment.

\section{RESUMEN}

La aspergilosis se refiere al espectro de enfermedades ocasionadas por la especie de Aspergillus. El aspergiloma es la forma más reconocida y común de la afección pulmonar relacionada a dicha especie, generalmente se desarrolla en una cavidad pulmonar pre-existente, la principal asociación es con secuelas de tuberculosis. Se desconoce la incidencia a nivel mundial. La mayoría de los pacientes se manifiestan asintomáticos; en raras ocasiones, debutan con hemoptisis mayor, con una mortalidad variable que oscila entre el 9 a 30\%. El diagnóstico se basa en los hallazgos clínicos, imagenología y confirmados por patología. El tratamiento farmacológico no ha demostrado ser de gran utilidad, en tanto que, la cirugía a pesar de una elevada morbilidad podría ser el tratamiento de elección. Palabras clave: Aspergiloma pulmonar, hemoptisis mayor, tratamiento quirúrgico.

\section{INTRODUCCIÓN}

La aspergilosis se produce como consecuencia de la inhalación de las esporas contenidas en el aire, por lo que los senos paranasales y los pulmones son los sitios en que se asienta la enfermedad con mayor frecuencia. Entre las diversas manifestaciones de esta micosis encontramos la forma Infecciosa conocida como aspergiloma pulmonar, la cual se presenta en pacientes con secuelas cavitarias y bronquiectasias ${ }^{(1-3)}$.

Para el diagnóstico de la enfermedad es importante contar con datos clínicos que permitan identificar antecedentes de alguna enfermedad que ocasione cavidades residuales o bronquiectasias (tuberculosis, sarcoidosis); además, la presencia de síntomas como hemoptisis y tos con expectoración convierte al paciente en altamente sospechoso.

Correspondencia: Dra. Andrea Parra Buitrago. Fax : (054)- 4125085

E-mail: andreaparrab@gmail.com

ISSN 07|8-332I Derechos reservados
Quisimos presentar este caso por tratarse de una paciente sin antecedentes pulmonares conocidos, quien cursó con infección por aspergiloma en medio de su inmunosupresión, y lo importante que fue la realización de manejo quirúrgico rápido de esta lesión para continuar el tratamiento de su enfermedad de base.

\section{PRESENTACIÓN DEL CASO}

Se trata de una paciente de II años de edad, con antecedentes de púrpura trombocitopénica y leucemia bifenotípica, diagnosticada en mayo de 2010 , en quimioterapia con remisión medular, quien consulta al servicio de oncología para inicio de nuevo ciclo de quimioterapia el 08/07/20 I0 donde encuentran disminución del murmullo vesicular en hemitórax derecho. Por ello se realiza una radiografía $(\mathrm{Rx})$ de tórax donde se evidencia la presencia de un neumotórax masivo derecho y 2 imágenes redondeadas de paredes gruesas (Figura I) por lo que decide su traslado al servicio de urgencias y posteriormente a cirugía para el paso de una sonda al tórax. 
La madre relata un cuadro clínico de I semana de evolución de tos inicialmente seca, luego húmeda, y desde hace 2 días con expectoración verdosa, si sangre, sin dificultad respiratoria. Al examen físico inicial destacó saturación de oxígeno $\left(\mathrm{O}_{2}\right)$ : 89\% con $\mathrm{FiO}_{2}$ : 27\%, FC: I30, PA: I45/70. Los hallazgos positivos: Ruidos respiratorios abolidos en hemitórax derecho, edema grado I en miembros inferiores, lesiones petequiales escasas en piel, abdomen y extremidades. Se le realiza al inicio una tomografía axial computada (TAC) de tórax que reporta condensación neumónica en la región periférica del segmento posterior del lóbulo pulmonar superior derecho, con lesión cavitada de pared engrosadas, e irregulares en forma difusa, mide $3 \mathrm{~cm}$ de diámetro mayor con contenido sólido e irregular de $2 \mathrm{~cm}$ de diámetro en su interior hallazgo en relación con bola de hongo-micetoma (posible aspergiloma) con patrón de vidrio esmerilado de parénquima pulmonar, segunda lesión cavitada en lóbulo medio derecho de 1,8 cm de diámetro (Figura 2).

Evaluada por neumología pediátrica quien considera que en paciente oncológica de base, la primera posibilidad sería un micetoma por aspergillus, sin descartar cándida, histoplasma, Pneumocistis jirovecii como agentes causales o coinfección asociada, se decide el inicio de Voriconazol y Trimetropin Sulfa y se realiza fibrobroncoscopia y lavado broncoalveolar, dando como resultado gram negativo para bacterias, micobacterias y estructuras micoticas. Se encuentra presencia de hifas hialinas septadas que sugieren aspergilosis, reacción en cadena de polimerasa (PCR) para micobacteria tuberculosis negativa, cultivos de aerobios de LBA y esputo negativos.

Llega la PCR para P. jiroveci negativa y prueba de galactomanan negativa: 0,1 . Oncología sugiere que es necesario resolución de proceso micótico para reinicio de quimioterapia, pero este tiempo no puede ser prolongado por riesgo de recaer en una leucemia de muy alto riesgo. La paciente estaba cursando con aspergillosis pulmonar invasora y a

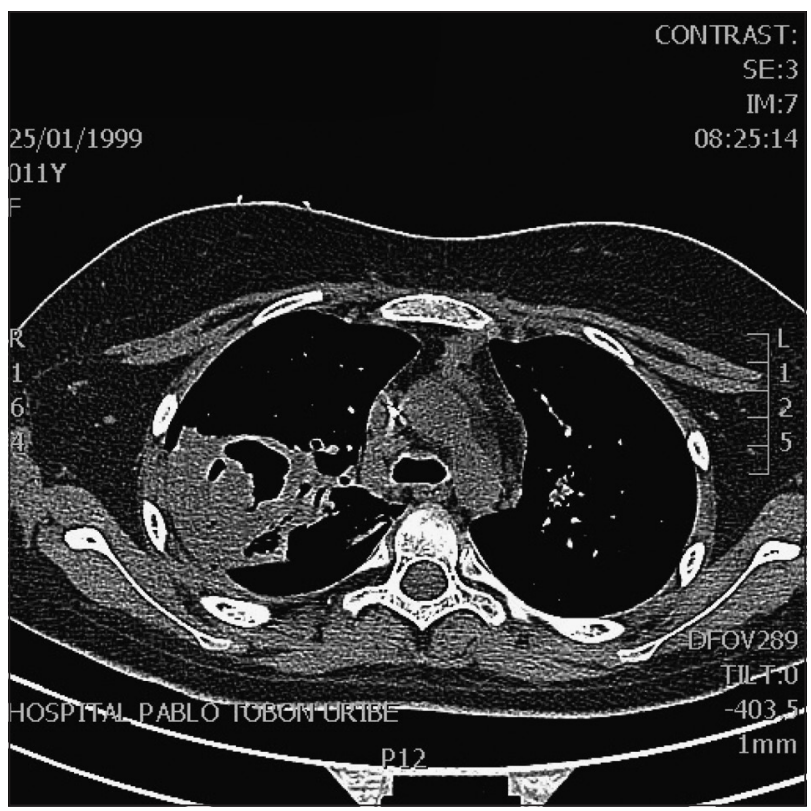

Figura 2. TAC de tórax que revela la presencia de un aspergiloma.

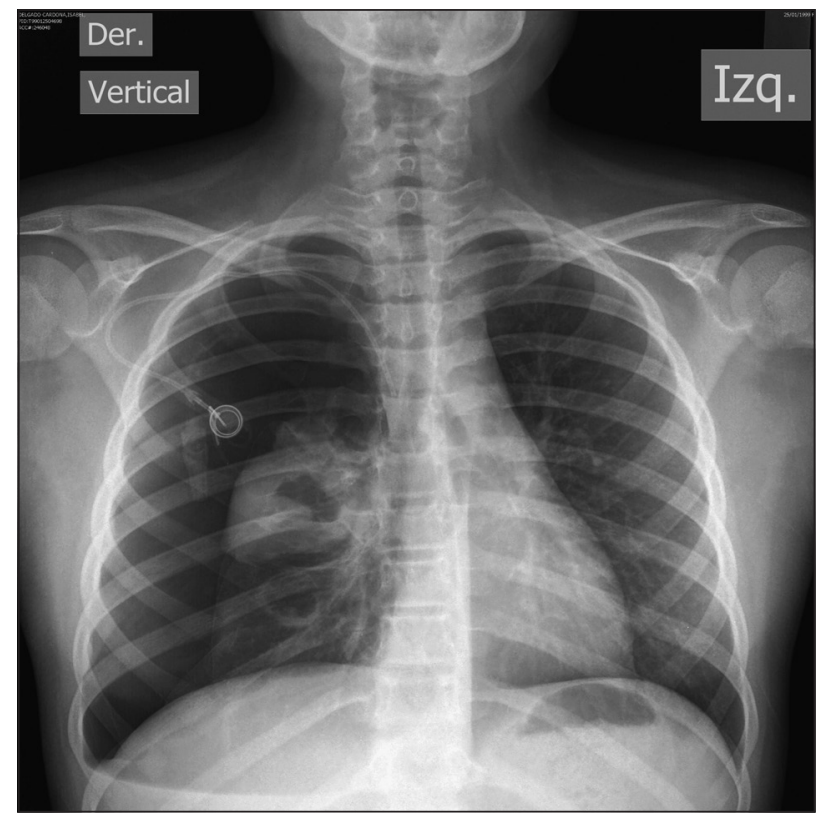

Figura I. Radiografía de tórax al ingreso al servicio de urgencias.

demás un posible aspergilloma. Por lo que se lleva a staff de decisión donde participan Neumología pediátrica, Oncología pediátrica, Infectología pediátrica, cirugía infantil, pediatría y se decide hacer manejo agresivo con resección quirúrgica de las lesiones pulmonares, minimizando el riesgo de nuevo neumotórax y reiniciar rápidamente quimioterapia para evitar recaída de la leucemia mieloide aguda.

Es llevada a cirugía el 16/07/20 I0 se realiza lobectomía superior pulmonar derecha, segmentomía lóbulo medio y del lóbulo inferior. Se reportan complicaciones: Sangrado importante, hallazgo inesperado de lesión en lóbulo inferior. Se traslada para vigilancia posoperatoria en Unidad de Cuidados Intensivos ( $\mathrm{UCI})$, queda con sonda a tórax, se realiza control de Rx postoperatorio (Figura 3). Llegan Cultivos de hongos

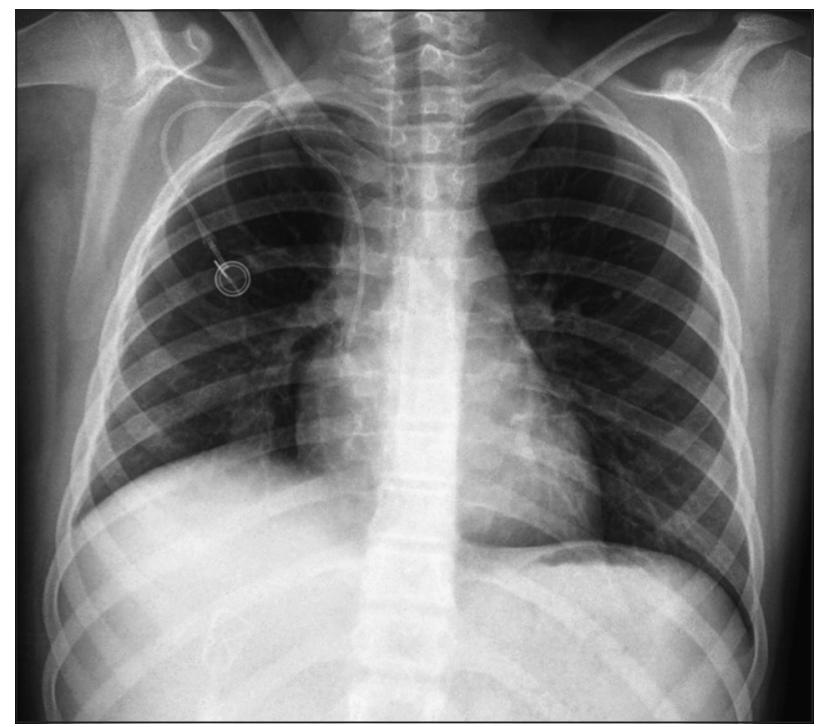

Figura 3. Radiografía de tórax de control postoperatorio. 
de tejido pulmonar con crecimiento de moho, cultivo de aerobios de tejido pulmonar negativos, tinciones para hongos, micobacterias, y bacterias negativas en tejido pulmonar, biopsia del lóbulo superior derecho positiva para aspergillus. Reporte negativo de galactomanan, por lo que se decide por su excelente respuesta clínica, inicio de quimioterapia el 28/07/2010.

Por parte de infectología se considera importante seguir tratamiento antimicótico mientras la paciente se encuentre inmunosuprimida por quimioterapia ya que la prueba de galactomanan es negativa y no sirve en este caso como parámetro de seguimiento de tratamiento. Paciente con muy buena evolución clínica, tolerancia al ciclo de quimioterapia luego de procedimiento quirúrgico e inicio de tratamiento antimicótico, recibió voriconazol IV desde el I I/07, cambio a vía oral el 19/07, el cual continúa mientras reciba quimioterapia, por 3 a 6 meses según evolución. Se decide su alta el 04/08/20 I 0 con cita de revisión en I mes por infectología, control ambulatorio por oncología pediátrica en 6 días con HLG de control, nueva quimioterapia e 15 días, TAC de tórax de control según evolución, continúa voriconazol mínimo de 3 a 6 meses, cita de revisión en 2 semanas por neumología pediátrica, pletismografia pulmonar al completar 4 semanas post cirugía para evaluar volúmenes pulmonares post resección.

\section{DISCUSIÓN}

La aspergilosis es una enfermedad micótica causada por la invasión tisular de la especie de aspergillus, más comúnmente A. fumigatus, A. flavus, A. terreus, A. niger ${ }^{(1)}$. Esta enfermedad puede ser pulmonar crónica, broncopulmonar alérgica 0 invasiva ${ }^{(2)}$. La aspergilosis pulmonar crónica tiene 4 manifestaciones principales: Aspergiloma, aspergilosis cavitada, fibrosis pulmonar, aspergilosis necrotizante ${ }^{(2)}$. Para interés de nuestro caso clínico describiremos el aspergiloma como la forma más común de aspergilosis pulmonar crónica.

El aspergiloma es una masa micótica compuesta por hifas de aspergillus, fibrina, moco, detritos celulares que se hallan en la cavidad pulmonar. Si es un aspergiloma simple se puede establecer por meses, y el paciente sólo sentir tos y poca evidencia de inflamación sistémica ${ }^{(3)}$. Los criterios diagnósticos son evidencia radiológica de masa redondeada en cavidad pulmonar combinado con evidencia microbiológica de aspergillus como agente causal( ${ }^{(4)}$. La diferencia entre un aspergiloma y una aspergilosis pulmonar cavitada son la sintomatología, evidencia de inflamación, apariencia radiológica y cambios en el tiempo. En pacientes inmunosuprimidos la enfermedad es de corta duración si se asocia a aspergilosis cavitada(').

La rápida detección del galactomanan por ELISA ha sido estudiado en numerosos grupos de pacientes con diagnóstico de aspergilosis invasiva y es útil ya que se detecta desde el crecimiento de la hifa(5). El análisis de este se realiza sólo en suero; sin embargo, se puede detectar el LCR, orina y $\mathrm{LBA}^{(6-9)}$. Los factores de riesgo para desarrollar la enfermedad son $^{(7-12)}$ : Neutropenia severa y prolongada, terapia con glucocorticoides, trasplante de células hematopoyéticas, trasplante de órgano sólido, SIDA, enfermedad granulomatosa crónica.
La aspergilosis invasiva generalmente se presenta como una infección progresiva aguda, los síntomas y signos dependen de la duración y del sitio anatómico involucrado(7), el compromiso pulmonar generalmente es la presentación más común en pacientes neutropénicos. La principal manifestación es fiebre, el dolor torácico, la tos y la hemoptisis. La combinación de dolor torácico pleurítico, disnea y hemoptisis sugieren la presencia de émbolos pulmonares en pacientes neutropénicos con trombocitopenia o sospecha de invasión vascular(8). Para el aspergiloma se ofrece resección quirúrgica para prevenir o tratar la hemoptisis y es usualmente curativo ${ }^{(9)}$.

Son indicaciones quirúrgicas ${ }^{18}$ : Pacientes con buena función respiratoria, enfermedad limitada a un lóbulo, enfermedad recurrente, intolerancia o resistencia a los azoles, o infección concomitante con un tumor. La terapia pre y post quirúrgica con voriconazol disminuye el riesgo de aspergilosis pleural ${ }^{(10-13)}$. El riesgo beneficio del tratamiento médico quirúrgico varia con las manifestaciones de la enfermedad y el estado pulmonar del paciente, por lo que debe ser individualizado ${ }^{(18)}$.

La aspergilosis es un diagnósitico que se debe tener en cuenta en todo paciente inmunosuprimido con neutropenia prolongada, o sometido a largas estancias en unidad de cuidados intensivos principalmente en pacientes con enfermedad pulmonar crónica, o con terapia de esteroides ${ }^{(|0,| l)}$. La invasión tisular de este hongo no es común y ocurre principalmente en pacientes inmunosuprimidos, como es el caso de nuestro paciente ${ }^{(10)}$.

La aspergilosis invasiva crónica puede ser vista con aspergilomas. La lenta progresión desde la infección hasta la formación del aspergiloma depende de la respuesta inmune del hospedero, donde se detecta la infección pero no la combate, manifestación presente en nuestro paciente debido a su condición patológica de base 10 . Aunque se ha descrito en la literatura que el diagnóstico temprano y el inicio oportuno de anti fúngicos tienen impacto en el pronóstico del paciente, no hay un método suficientemente sensible y específico para el diagnóstico(11,12).

Estudios prospectivos han demostrado el papel diagnóstico de métodos como el antígeno galactomanan, pero en pacientes con malignidades hematológicas puede dar negativa, por lo tanto, sólo debe usarse para predecir resultados en pacientes con aspergilosis invasiva. En pacientes severamente enfermos la confirmación histopatológica no es posible o en pacientes con trombocitopenia que contraindique la biopsia, por lo que sólo la identificación el lavado broncoalveolar es suficiente para inicio del tratamiento, como sucedió con nuestro caso ${ }^{(5,9,11-14)}$.

Esta colonización fúngica se localiza en cavidades pulmonares pre-existentes, generalmente debido a lesiones tuberculosas, pero puede ocurrir dentro de cavidades de etiologías diversas como la sarcoidosis, bronquiectasias, quistes, neoplasias, espondilitis anquilosante, granulomatosis de Wegener, entre otras. Puede tener un curso prolongado, por lo cual se ha propuesto el manejo quirúrgico como una alternativa. La polémica en torno al manejo quirúrgico se debe a la morbimortalidad de la cirugía.

En el aspergiloma pulmonar, el manejo quirúrgico conocido desde hace un siglo y medio genera aun controversia, 
pero un marcado descenso en la mortalidad ahora, ha llevado a su mayor aceptación en los últimos años. Aunque la terapia antifúngica ha sido utilizada, este tipo de tratamiento ha mostrado resultados parciales. El éxito del tratamiento del aspergiloma complejo necesita ambas, cirugía y farmacoterapia perioperatoria. El alto índice de sospecha constituye la clave del éxito y un diagnóstico oportuno es de vital importancia para estos pacientes ya que el manejo quirúrgico precoz reduce el tiempo de estancia hospitalaria, y el tiempo de tratamiento antinfúgico, controlando mejor la infección y con resultados totales de erradicación, permitiendo mejores tasas de curación y reiniciación temprana de quimioterapia. Con esta presentación de caso, queda abierta la posibilidad de hacer otros estudios donde se pueda evaluar la frecuencia de esta enfermedad en nuestro medio y la respuesta al manejo quirúrgico del aspergiloma, el cual en nuestro caso fue exitoso.

\section{REFERENCIAS}

I. Morgan J, Wannemuehler KA, Marr KA, et al. Incidence of invasive aspergillosis following hematopoietic stem cell and solid organ transplantation: interim results of a prospective multicenter surveillance program. Med Mycol 2005; 43 Suppl I: S49.

2. Denning, DW, Riniotis, K, Dobrashian, R, Sambatakou, H. Chronic cavitary and fibrosing pulmonary and pleural aspergillosis: case series, proposed nomenclature change, and review. Clin Infect Dis 2003; 37 Suppl 3: S265.

3. Judson, MA, Stevens, DA. The treatment of pulmonary aspergilloma. Curr Opin Investig Drugs 200 I; 2: 1375.

4. Hope, WW, Walsh, TJ, Denning, DW. The invasive and saprophytic syndromes due to Aspergillus spp. Med Mycol 2005; 43 Suppl I: S207.

5. Maertens, J, Van Eldere, J, Verhaegen, J, et al. Use of circulating galactomannan screening for early diagnosis of invasive aspergillosis in allogeneic stem cell transplant recipients. J Infect Dis 2002; I86: 1297.

6. Klont, RR, Mennink-Kersten, MA, Verweij, PE. Utility of Aspergillus antigen detection in specimens other than serum specimens. Clin Infect Dis 2004; 39: 1467.

7. Schwartz, S, Thiel, E. Clinical presentation of invasive aspergillosis. Mycoses 1997; 40 Suppl 2: 21 .

8. Hachem, R, Sumoza, D, Hanna, H, et al. Clinical and radiologic predictors of invasive pulmonary aspergillosis in cancer patients: should the European Organization for Research and Treatment of Cancer/Mycosis Study Group (EORTC/MSG) criteria be revised? Cancer 2006; 106: 1581.

9. Walsh, TJ, Anaissie, EJ, Denning, DW, et al. Treatment of aspergillosis: clinical practice guidelines of the Infectious Diseases Society of America. Clin Infect Dis 2008; 46: 327.

10. Binder, RE, Faling, LJ, Pugatch, RD, et al. Chronic necrotizing pulmonary aspergillosis: a discrete clinical entity. Medicine (Baltimore) 1982; 61: 109. 